\title{
Prevalence and Associated Factors of Post- Traumatic Stress Disorder (PTSD) Among a Cohort of Post-Partum Sri Lankan women: A Cross Sectional Study
}

Wedisha Imal Gankanda ( $\square$ wedisha@yahoo.com )

Colombo South Teaching Hospital https://orcid.org/0000-0002-9818-4236

\section{I.A.G.M.P Gunathilake}

National Institute of Mental Health

N.L. Kahawala

Medical officer of health office, Horana

A.K.P. Ranaweera

Faculty of Medicine,University of Colombo

Research article

Keywords: PTSD, Post-partum PTSD, Post-partum depression, PSS-SR, PDSS

Posted Date: December 3rd, 2020

DOl: https://doi.org/10.21203/rs.3.rs-119075/v1

License: (c) (1) This work is licensed under a Creative Commons Attribution 4.0 International License.

Read Full License 


\section{Abstract}

\section{Background}

Post-Traumatic Stress Disorder (PTSD) usually follows a catastrophic event. However, the experience of child birth can be severe enough to cause PTSD in some women.

\section{Methods}

A cross-sectional study was conducted in field clinics of a semi-urban area. A pre-tested interviewer administered checklist was used to collect socio-demographic and pregnancy related data. Pre-existing self-administered, validated Sinhalese versions of the Edinburgh Postnatal Depression Scale (EPDS) and PTSD Symptom Scale-Self Report (PSS-SR) were used to assess the presence of Post-Partum Depression (PPD) and PTSD, respectively. Each participant was assessed at one, two and six months after the delivery for PTSD and PPD. Scores of PPD $>9$ and PSS-SR $>13$ were taken as positive for the two conditions, respectively.

\section{Results}

Data was obtained from 225 women who were at their first month postpartum, for the initial study. The response rate at their follow-up visits at the second and sixth months were 95\% $(n=214)$ and $94 \%$ $(n=211)$. The point prevalence of postpartum PTSD was recorded as $2.7 \%(n=6), 0.9 \%(n=2)$ and $0.5 \%$ $(n=1)$ at their first, second and sixth month postpartum, respectively. A period prevalence of $3.6 \%$ was observed over 6 months. Verbal abuse during labour $(p=0.04)$ and the presence of postpartum depression $(P \leq 0.001)$ were significantly associated with postpartum PTSD. There were no significant associations between PTSD and gestational age at delivery, whether it was a pregnancy planned ahead or not, a history of subfertility, family history of psychiatric disorders, intimate partner violence, receiving antenatal counseling, type and mode of delivery, duration of labour, presence of a labour companion, mental trauma, presence of post-partum hemorrhage, manual removal of placenta, negative birth experience, low APGAR score of the baby at delivery, receiving neonatal and maternal intensive care, birth defects, problems with breast feeding or opportunities to discuss problems with a health care worker.

\section{Conclusions}

Prevalence of postpartum PTSD in this semi-urban community during the study period was $3.6 \%$; which is in par with the overall global prevalence. PTSD was significantly associated with verbal abuse during labour and postpartum depression.

\section{Background}

"Stress" is defined as a response of oneself to a change in the environment, which may be adaptive or non-adaptive. A normal stress response is adaptive and beneficial. Nevertheless, non-adaptive stress responses like Post Traumatic Stress Disorder (PTSD) can impair normal functionality (1). 
Affected individuals of PTSD present with a characteristic triad of re-experiencing the symptoms (flashbacks, nightmares), avoidance of symptoms (staying away from reminders) (2) and symptoms of arousal/reactivity developing over few weeks to several months after exposure, in the absence of an organic cause. PTSD usually occurs in people who have experienced an exceptionally shocking, threatening or catastrophic event.

Birthing is a positive experience for most women; however, it can be daunting in a minority of them. Traumatic child birth is a recognized risk factor for developing postpartum PTSD (3). Therefore, it is postulated that intense physical and mental stressors associated with child birth lead to PTSD in the postpartum period in some pregnant women. Furthermore, PTSD is a condition associated with PostPartum Depression (PPD), violence, suicide (3), as well as relationship problems (1) and fertility issues (4). If not detected, it puts both the mother and newborn at risk. As early identification and intervention will minimize the risk to the mother and newborn, it is imperative that both obstetric and mental health caregivers promptly recognize this subset of mothers who develop postpartum PTSD.

Currently, routine screening is being done for postpartum depression (PPD) successfully in postpartum clinics. However, in the recent past, there is a growing concern amongst the medical profession that some mothers having PTSD are being misdiagnosed and labelled to be having PPD. This can lead to detrimental outcomes for mothers with PTSD as the management of PTSD is different to that of PPD (5).

Postpartum PTSD had been a subject of extensive study worldwide with a global prevalence of $3.17 \%$ (6). However, published data is very limited within the South Asian region. Therefore, it is important to determine the hidden burden of PTSD and the factors associated with it in order to take necessary remedial actions.

Accordingly, this study was conducted with a view of describing the prevalence and associated factors of Post Traumatic Stress Disorder among a cohort of postpartum mothers.

\section{Methods}

A cross sectional study at three different points of time, with an analytical component, was conducted at four randomly selected field clinics located in the Horana $\mathrm{MOH}$ area. Two hundred and twenty-five postpartum mothers after their first month of delivery, who had no previous diagnosis of a psychiatric illness were included in the study.

Data collection was done using an interviewer administered checklist for socio-demographic data, and a Sinhalese validated self-administered questionnaire, the PTSD Symptom Scale-Self Report: PSS-SR (7) to assess PTSD symptoms, and the Sinhalese validated self-administered Edinburgh Postpartum Depression Screening Scale: PDSS (8) to assess the postpartum depression. Both of these questionnaires have been used in similar studies in Sri Lanka $(7,8)$. Postpartum PTSD was taken as a PSS-SR score $>13$. Follow up of the same individuals during their second and sixth months postpartum 
was done, where they were repeatedly offered the self-administered questionnaires of the PSS-SR scale and EPDS scale.

A pilot study was conducted in a polyclinic in the Horana $\mathrm{MOH}$ area which is not included in the study, to assess the practicality and feasibility in carrying out the data collection.

Ethical clearance was obtained from the Ethical Review Committee of the Faculty of Medicine, University of Colombo (Ref No:EC-16-169). The information sheet was explained to each participant and verbal consent was obtained.

Verbal consent was deemed more appropriate by the Ethical Review Committee, since a government-led mandatory post-natal screening (using EPDS) was already in place in the same clinics, for which verbal consent alone was being taken.

This similar non-interventional study has no more than minimal risks to its subjects, making verbal consent sufficient for this setting. In addition, the only record linking the subject to the study would be the consent form, therefore, in order to protect the anonymity of the subjects, verbal consent was taken.

Statistical analysis was performed using the SPSS statistical package version 18.

\section{Results}

Two hundred and twenty-five mothers at one-month post-partum were included in the study. Out of them 214 and 211 were re-evaluated at the second and sixth months post-partum. The attrition was very less since $93.8 \%(n=211)$ of the post-partum mothers participated at the end of the sixth month as well. The mean age of the mothers is 28.38 years $(S D=5.52)$, while the median age is 28 years with a minimum of 15 years and maximum of 42 years. Among the participants of the study, $40.9 \%(n=92)$ had an education level above the GCE ordinary level (O/L).

The prevalence of PPD among the study participants was 7.1\% $(n=16), 4.2 \%(n=9)$ and $0.9 \%(n=2)$ at the first, second and sixth month postpartum, respectively. Altogether $24(10.4 \%)$ had developed PTSD following delivery up to 6 months.

\section{Prevalence Of Postpartum Ptsd}

Figure 1 summarizes the prevalence of PTSD during the study period.

At the first, second and sixth month postpartum, the prevalence of PTSD was $2.7 \%(n=6), 0.9 \%(n=2)$ and $0.5 \%(n=1)$, respectively. Altogether $8(3.6 \%)$ had developed PTSD following delivery up to 6 months.

\section{Factors Associated With Postpartum Ptsd}




\section{Pre-pregnancy factors}

Table 1 depicts the association between postpartum PTSD and pre-pregnancy factors; family history of mental illness, level of education of the mother and intimate partner violence were not significantly associated with postpartum PTSD.

Table 1

Pre-pregnancy factors and association with postpartum PTSD

\begin{tabular}{|c|c|c|c|c|c|}
\hline \multicolumn{2}{|l|}{ Factor } & \multicolumn{2}{|l|}{ PTSD } & \multirow{3}{*}{$\begin{array}{l}\text { Total } \\
\text { No. }\end{array}$} & \multirow{3}{*}{$\begin{array}{l}\text { Fishers' exact test (2- } \\
\text { sided) } \\
\text { p value * }\end{array}$} \\
\hline & & \multirow{2}{*}{$\begin{array}{l}\text { Yes } \\
\begin{array}{l}\text { No. } \\
(\%)\end{array}\end{array}$} & 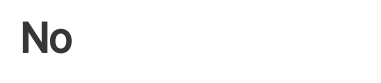 & & \\
\hline & & & No. (\%) & & \\
\hline \multirow{2}{*}{$\begin{array}{l}\text { Family history of mental } \\
\text { illness }\end{array}$} & Yes & $0(0)$ & $5(100)$ & 5 & $p=1.00$ \\
\hline & No & $8(3.6)$ & $212(96.4)$ & 220 & \\
\hline \multirow[t]{2}{*}{ Level of education } & $<=0 / L^{* *}$ & $6(4.5)$ & $126(95.5)$ & 131 & $p=0.48$ \\
\hline & $>0 / L$ & $2(2.1)$ & 91(97.9) & 92 & \\
\hline \multirow[t]{2}{*}{ Intimate Partner violence } & Yes & $0(100)$ & $3(100)$ & 3 & $p=1.00$ \\
\hline & No & $8(3.6)$ & $214(96.4)$ & 222 & \\
\hline Total & & 8 & 217 & 225 & \\
\hline
\end{tabular}

\section{Antenatal factors}

Table 2 describes the antenatal factors associated with postpartum PTSD. None of the factors below were significantly associated with the development of postpartum PTSD. 
Table 2

Antenatal factors and association with postpartum PTSD.

\begin{tabular}{|c|c|c|c|c|c|}
\hline \multicolumn{2}{|l|}{ Factor } & \multicolumn{2}{|l|}{ PTSD } & \multirow[t]{2}{*}{ Total } & \multirow{3}{*}{$\begin{array}{l}\text { Fishers' exact test (2-sided) } \\
\text { p value* }^{*}\end{array}$} \\
\hline & & \multirow{2}{*}{$\begin{array}{l}\text { Yes } \\
\text { No. } \\
\text { (\%) }\end{array}$} & No & & \\
\hline & & & No. (\%) & No. & \\
\hline \multirow[t]{2}{*}{ Parity } & 1 & $6(6.3)$ & $90(93.8)$ & 96 & $p=0.08$ \\
\hline & $>1$ & $2(1.6)$ & $127(98.4)$ & 129 & \\
\hline \multirow[t]{2}{*}{ Planned pregnancy } & Yes & $4(3)$ & $128(97)$ & 132 & $p=0.72$ \\
\hline & No & $4(4.3)$ & $89(95.7)$ & 93 & \\
\hline \multirow[t]{2}{*}{ History of subfertility } & Yes & $0(0)$ & $17(100)$ & 17 & $p=1.00$ \\
\hline & No & $8(3.8)$ & $200(96.2)$ & 208 & \\
\hline \multirow{2}{*}{$\begin{array}{l}\text { Number of antenatal clinic } \\
\text { visits }\end{array}$} & $<4$ & $1(6.7)$ & 14(93.3) & 15 & $p=0.47$ \\
\hline & $>=4$ & $7(3.4)$ & 201(96.6) & 208 & \\
\hline \multirow[t]{2}{*}{ Receiving antenatal advice } & Yes & $8(3.7)$ & 209(96.3) & 217 & $p=1.00$ \\
\hline & No & 0 & $8(100)$ & 8 & \\
\hline \multirow{2}{*}{$\begin{array}{l}\text { Inter-pregnancy } \\
\text { interval(years)** }\end{array}$} & $<=2$ & $0(0)$ & $12(100)$ & 12 & $p=1.00$ \\
\hline & $>2$ & $2(1.7)$ & 115(98.3) & 117 & \\
\hline Total & & 8 & 217 & & \\
\hline
\end{tabular}

\section{Intra-partum Factors}

Table 3 describes the association of antenatal factors with postpartum PTSD. Verbal abuse in labour was significantly associated with postpartum PTSD. 
Table 3

Association of Intra-partum factors with postpartum PTSD.

\begin{tabular}{|c|c|c|c|c|c|}
\hline \multirow[t]{3}{*}{ Factor } & & \multicolumn{2}{|l|}{ PTSD } & \multirow{3}{*}{$\begin{array}{l}\text { Total } \\
\text { No. }\end{array}$} & \multirow{3}{*}{$\begin{array}{l}\text { Fishers' } \\
\text { exact test } \\
\text { (2-sided) } \\
\text { p value* }\end{array}$} \\
\hline & & \multirow{2}{*}{$\begin{array}{l}\text { Yes } \\
\text { No. (\%) }\end{array}$} & \multirow{2}{*}{$\begin{array}{l}\text { No } \\
\text { No. (\%) }\end{array}$} & & \\
\hline & & & & & \\
\hline \multirow[t]{2}{*}{ Maturity at birth } & Preterm & $2(1.6)$ & $127(98.4)$ & 129 & $p=0.06$ \\
\hline & Term & $6(6.3)$ & $90(93.8 \%)$ & 96 & \\
\hline \multirow[t]{2}{*}{ Type of hospital } & State & $7(3.7)$ & $184(96.3)$ & 191 & $p=1.00$ \\
\hline & Private/other & $1(2.9)$ & $33(97.1)$ & 34 & \\
\hline \multirow[t]{2}{*}{ Fear of anticipated pain } & Yes & $4(8)$ & 46(92) & 50 & $p=0.054$ \\
\hline & No & $4(2.3)$ & 171(97.7) & 175 & \\
\hline \multirow[t]{2}{*}{ Verbal abuse during labour } & Yes & $1(12.5)$ & $7(87.5)$ & 8 & $p=0.04$ \\
\hline & No & $2(0.9)$ & 215(99.1) & 217 & \\
\hline \multirow[t]{2}{*}{ Physical abuse during labour } & Yes & $0(0)$ & $1(100)$ & 1 & $p=1.00$ \\
\hline & No & $8(3.6)$ & 216(96.4) & 224 & \\
\hline \multirow[t]{2}{*}{ Presence of labour companion } & Yes & $1(2.6)$ & $37(97.4)$ & 38 & $p=1.00$ \\
\hline & No & $7(3.7)$ & $180(96.3)$ & 187 & \\
\hline \multirow[t]{4}{*}{ Mode of delivery } & Vaginal & $3(2.3)$ & $125(97.7)$ & 128 & $p=0.50$ \\
\hline & Vacuum/Forceps & $0(0)$ & $5(100)$ & 5 & \\
\hline & EL-LSCS & $4(4.9)$ & $78(95.1)$ & 82 & \\
\hline & EM-LSCS & $1(10)$ & $9(90)$ & 10 & \\
\hline \multirow{2}{*}{$\begin{array}{l}\text { Perception of labour as negative } \\
\text { experience }\end{array}$} & Yes & $0(0)$ & $10(100)$ & 10 & $p=1.00$ \\
\hline & No & $8(3.6)$ & $207(96.3)$ & 215 & \\
\hline \multirow[t]{2}{*}{ Duration of active labour(hours)** } & $<4$ & $3(2.5)$ & $119(97.5)$ & 122 & $p=0.29$ \\
\hline & $4-8$ & $1(3.8)$ & $25(96.2)$ & 26 & \\
\hline
\end{tabular}


Total

*Used this test since there are some cells with values $<5, p=p$ value

** Total $=156$ since certain mothers underwent LSCS without experiencing a labour

\section{Postpartum Factors}

Table 4 describes the postpartum factors associated with postpartum PTSD. Concomitant postpartum depression was significantly associated with postpartum PTSD. 
Table 4

Postpartum factors and association with postpartum PTSD.

\begin{tabular}{|c|c|c|c|c|c|}
\hline \multirow[t]{3}{*}{ Factor } & & \multicolumn{2}{|l|}{ PTSD } & \multirow{3}{*}{$\begin{array}{l}\text { Total } \\
\text { No. }\end{array}$} & \multirow{3}{*}{$\begin{array}{l}\text { Fishers' exact test } \\
\text { (2-sided) } \\
\text { p value* }\end{array}$} \\
\hline & & \multirow{2}{*}{$\begin{array}{l}\text { Yes } \\
\text { No. (\%) }\end{array}$} & \multirow{2}{*}{$\begin{array}{l}\text { No } \\
\text { No. (\%) }\end{array}$} & & \\
\hline & & & & & \\
\hline \multirow[t]{2}{*}{ PPH } & Yes & $0(0)$ & $8(100)$ & 8 & $p=1.00$ \\
\hline & No & $8(3.6)$ & $209(96.4)$ & 217 & \\
\hline \multirow[t]{2}{*}{ Manual removal of placenta } & Yes & $0(0)$ & $7(100)$ & 7 & $p=1.00$ \\
\hline & No & $8(3.6)$ & $210(96.4)$ & 218 & \\
\hline \multirow[t]{2}{*}{ Baby cried after birth } & Yes & $8(3.7)$ & $208(96.3)$ & 216 & $p=1.00$ \\
\hline & No & $0(0)$ & $9(100)$ & 9 & \\
\hline \multirow[t]{2}{*}{ Mother: ICU admission } & Yes & $0(0)$ & $6(100)$ & 6 & $p=1.00$ \\
\hline & No & $8(3.6)$ & 211(96.4) & 219 & \\
\hline \multirow[t]{2}{*}{ Baby: PBU admission } & Yes & $1(4.5)$ & $21(95.5)$ & 22 & $p=0.57$ \\
\hline & No & $7(3.4)$ & 196(96.6) & 224 & \\
\hline \multirow[t]{2}{*}{ Baby: NICU admission } & Yes & $1(4.7)$ & $20(95.3)$ & 21 & $p=0.55$ \\
\hline & No & $7(3.4)$ & $197(96.6)$ & 204 & \\
\hline \multirow[t]{2}{*}{ Baby: Presence of birth defects } & Yes & $0(0)$ & 14(100) & 14 & $p=1.00$ \\
\hline & No & $8(3.7)$ & 203(97.7) & 211 & \\
\hline \multirow[t]{2}{*}{ Breast feeding } & Yes & $8(3.6)$ & 211(96.7) & 219 & $p=1.00$ \\
\hline & No & $0(0)$ & $6(100)$ & 6 & \\
\hline \multirow[t]{2}{*}{ Family support } & Yes & $7(3.2)$ & 212(96.8) & 219 & $p=0.20$ \\
\hline & No & $1(1.7)$ & $5(98.3)$ & 6 & \\
\hline \multirow[t]{2}{*}{ Readmission } & Yes & $2(6.4)$ & $29(93.6)$ & 31 & $p=0.30$ \\
\hline & No & $6(3.1)$ & $188(96.9)$ & 194 & \\
\hline Physical ailments & Yes & $3(8.1)$ & $34(91.7)$ & 37 & $p=0.13$ \\
\hline
\end{tabular}




\begin{tabular}{|lllllll|}
\hline & No & $5(2.6)$ & $183(97.3)$ & 188 & \\
\hline Opportunity to discuss concerns & Yes & $2(2.8)$ & $69(97.2)$ & 71 & $\mathrm{p}=1.00$ \\
\cline { 2 - 7 } & No & $6(3.9)$ & $148(96.1)$ & 154 & \\
\hline Postpartum depression & Yes & $6(25)$ & $18(75)$ & 24 & $\mathrm{p}<0.001$ \\
\cline { 2 - 7 } & No & $2(1)$ & $199(99)$ & 201 & \\
\hline Total & & 8 & 217 & 225 & \\
\hline *Used this test since there are some cells with values $<5, \mathrm{p}=\mathrm{p}$ value & \\
\hline
\end{tabular}

\section{Discussion}

In this study, the prevalence of PTSD at one, two and six months postpartum, was $2.7 \%(n=6), 0.9 \%$ ( $n=$ $2)$ and $0.5 \%(n=1)$, respectively and the overall prevalence was $3.6 \%$. These are comparable to the prevalence rates of most of the studies done in other countries. Several cross-sectional studies, including those conducted in Iran and Nigeria, have found that the prevalence of postpartum PTSD after one month of delivery was in the range of 1.2-9.4\% (4). A meta-analysis including 50 studies $(N=21,429)$ from 15 countries studying PTSD symptoms in postpartum mothers showed a global prevalence of $3.17 \%$ at one month postpartum, which is compatible with the findings of this study (6).

A Serbian study which was conducted using a scale which is different to the tool used in this study, the Clinician-Administered PTSD Scale (CAPS), also supports similar rates of postpartum PTSD at the first month which was $2.4 \%$ (10). However, the same study found that $9.5 \%$ of the mothers had a clinically significant level of disabling PTSD symptoms (partial PTSD), which was not amounting to the full disorder. Moreover, at the second and the third months postpartum, the prevalence of partial PTSD 5.9\% and $1.3 \%$, respectively, while none of the participants had full PTSD (10). Symptoms of partial PTSD were not analyzed in our study, as the validated tool used did not categorize them specifically. However, the pattern found in the Serbian study is similar to our study, as rates of full PTSD was seen to follow a declining trend with time (at two and six months, prevalence of PTSD being $0.9 \%$ and $0.5 \%$, respectively) suggesting a probable self-limiting natural course of the condition over time.

Various studies have found different prevalence rates. A two staged study conducted in the USA, using the same tool used in this study, the PTSD Symptom Scale-Self Report (PSS-SR), found a higher prevalence of postpartum PTSD of $9 \%$ after 1 month, while $18 \%$ experienced high levels of post-traumatic symptoms (partial postpartum PTSD) (9). Another cross sectional study done in a fetal high-risk maternity hospital in the city of Rio de Janeiro, Brazil, using a different tool, the "Stress Disorder Checklist; PCL-C", found a higher prevalence (9.4\%) of post-partum PTSD (10). Socio-cultural differences between the two countries may have played a role in these observed differences of prevalence. The study done in 
Brazil included a selected high-risk population for postpartum PTSD (mothers with pregnancy complications and high fetal risk).

Some studies demonstrate a lower prevalence compared to this study. A Dutch study (11) involving 428 women shows a prevalence of $1.2 \%$. A Swedish study of 1640 postpartum mothers, that used the Traumatic Event Scale (TES), shows a prevalence of PTSD of 1.7\%. (12). Socio-cultural factors, levels of obstetric care and the usage of different scales may play a role in these observed differences.

In our study, only two significant associations with postpartum PTSD were demonstrate; Verbal abuse during labour $(p=0.04)$ and presence of Postpartum Depression (PPD) $(P=<0.001)$. There are several studies and a meta-analysis in favor of the presence of PPD being a well-documented risk factor for postpartum PTSD $(5-7,12)$. In contrast, very few studies had specifically looked into the effect of verbal abuse during labour on the development of PTSD (4).

According to studies worldwide, several factors associated with the development of PTSD following childbirth have been identified. Among the known pre-pregnancy associated factors, low educational level (14), unplanned pregnancy (9),fear of child birth (6), family history of mental disease (6), nulliparity (12) or three or more previous births (10) were not found to be significantly associated with postpartum PTSD in our study.

Intra-pregnancy factors associated with postpartum PTSD include gestational age at delivery (14), number of antenatal care visits (14), poor health or complications in pregnancy (6), hospital admission due to pregnancy complications [OR 11.86 (95\% Cl: 6.36-22.10)] (15), increased fear of childbirth (10), higher expected intensity of pain (10) and intimate partner violence (10). However, none of these factors showed a significant association with postpartum PTSD in our study.

Documented intra-partum factors associated with postpartum PTSD are, duration of labour (14), mode of delivery (14), negative subjective birth experiences (6), having an operative birth (operative vaginal or caesarean section) $(6,15)$, lack of support $(6)$ and poor maternal experience of control during childbirth [OR 5.05(95\% Cl: 2.69-9.48)] (15). However, none of these factors were significantly associated with PTSD in our study.

Among documented postpartum factors found to be associated with postpartum PTSD are poor neonatal outcome (10), low neonatal APGAR Score at delivery (7), neonatal and maternal intensive care (5), birth defects (4), lack of support from family and partner $(6,9)$, postpartum physical problems (9), lack of exclusive breast feeding at one month (9) and not having an opportunity to discuss concerns with health care staff about mental wellbeing (9). In our study, none of these associations reached the level of significance. Possible reasons for the lack of association may be the total sample size and number of mothers with postpartum PTSD being lesser than expected.

Being a small sample size, there is a limitation in generalizing these results to the entire population of the country where social and economic backgrounds might differ. Since this is a cross sectional study, it is 
difficult to establish the exact temporal relationships between the associated factors (e.g. when PPD and PTSD both present at the time of data collection, it is uncertain which developed earlier). Partial PTSD patients were not analyzed since the validated study instrument used did not specifically categorize them.

\section{Conclusions}

PTSD is a postpartum psychiatric condition prevalent in this community, with an overall prevalence of $3.6 \%$ over 6 months. Verbal abuse during labour $(p=0.04)$ and presence of PPD $(p=<0.001)$ were significantly associated with the development of post-partum PTSD. There were no significant association between PTSD and education level of mothers, timing of delivery, gap between pregnancies, whether the pregnancy was pre-planned, history of subfertility, history of psychiatric disorders, intimate partner violence, number of antenatal hospital visits, type of hospital, mode of delivery, labour duration, physical abuse, presence of labour companion, mental trauma, postpartum hemorrhage, manual removal of placenta, negative birth experience, low neonatal APGAR score at delivery, receiving neonatal and maternal intensive care, birth defects, problems with breast feeding and opportunity to discuss problems with a health care worker.

\section{Recommendations}

There is an urgent requirement to provide awareness and training to the primary care health care staff on prompt identification of postpartum PTSD.

It is necessary to introduce a validated questionnaire to detect post-partum PTSD symptoms. A short questionnaire checking key symptoms of postpartum PTSD (like avoidance and flashbacks related to childbirth) would be helpful for rapid identification and prompt referral for management by a psychiatrist. It is a feasible option since a similar screening method and referral pathway is already existent in screening for postpartum depression.

\section{Abbreviations}

EPDS Edinburgh Postnatal Depression Scale

GCE General Certificate of Education

ICU Intensive care unit

$\mathrm{MOH}$ Medical Officer of Health

NICU Neonatal Intensive Care Unit

PBU Premature Baby Unit 
PPD Post-partum depression

PPH Post-partum haemorrhage

PSS-SR PTSD Symptom Scale-Self Report

PTSD Post-traumatic stress disorder

SD Standard Deviation

SPSS Statistical Package for the Social Sciences

TES Traumatic event scale

\section{Declarations}

\section{Ethics approval and consent to participate}

Consent from participants was taken and ethical approval was granted by the Faculty of Medicine, University of Colombo.

\section{Consent for publication}

Not applicable.

\section{Competing interests}

There are no competing interests

\section{Funding}

No funding was received for this study

\section{Authors' contributions}

WIG- design of the work, acquisition, entering and interpreting of data, drafting, revision

IAGMPG- design of the work, interpretation of data, drafting, revision

NLK- design of the work, acquisition, drafting

AKPR- design of the work, interpretation of data, revision

All authors have read and approved the manuscript.

\section{Acknowledgements}


Authors would like to acknowledge staff of the $\mathrm{MOH}$ office, Horana

\section{Availability of data and materials}

Original data is available with the authors and data file can be accessed from the repository (https://www.synapse.org/\#!Synapse:syn23583521) on request from the corresponding author.

\section{References}

1. Peeler S, Stedmon J, Chung M, Skirton H. Women's experiences of living with postnatal PTSD. Midwifery. 2018;56:70-8.

2. WHO. The ICD-10 classification of mental and behavioural disorders: clinical descriptions and diagnostic guidelines 10th Revision. WHO. Geneva: World Health Organization; 1992.

3. Post-traumatic stress. disorder: management | Guidance and guidelines | NICE. NICE; 2015.

4. Gottvall K, Waldenstrom U. Does a traumatic birth experience have an impact on future reproduction? BJOG: An Int J Obstet Gynaecol. 2002;109(3):254-60.

5. Kay chaudry. Is it Postnatal Depression or Birth Trauma(PTSD) [Internet]. 2014. Available from: https://www.linkedin.com/pulse/20140521172127-95845674-is-it-postnatal-depression-or-birthtrauma-ptsd.

6. Ayers S, Bond R, Bertullies S, Wijma K. The aetiology of post-traumatic stress following childbirth: a meta-analysis and theoretical framework. Psychol Med. 2016;46(6):1121-34.

7. Hollifield M, Hewage C, Gunawardena CN, Kodituwakku P, Bopagoda K, Weerarathnege K. Symptoms and coping in Sri Lanka 20-21 months after the 2004 tsunami. Br J Psychiatry [Internet]. 2008 Jan [cited 2016 Jul 8];192(1):39-44. Available from: http://www.ncbi.nlm.nih.gov/pubmed/18174508.

8. Rowel D, Jayawardana P, Fernando N, Association SLM. Validation of the Sinhala translation of Edinburgh Postnatal Depression Scale. Ceylon Med J [Internet]. 2008;53(1):10-3. Available from: http://repository.kln.ac.lk/handle/123456789/1880.

9. Beck CT, Gable RK, Sakala C, Declercq ER. Posttraumatic stress disorder in new mothers: results from a two-stage U.S. national survey. Birth [Internet]. 2011 Sep [cited 2016 Jul 31];38(3):216-27. Available from: http://www.ncbi.nlm.nih.gov/pubmed/21884230.

10. Henriques T, de Moraes CL, Reichenheim ME, de Azevedo GL, Coutinho ESF, Figueira IL de V. Postpartum posttraumatic stress disorder in a fetal high-risk maternity hospital in the city of Rio de Janeiro, Brazil. Cad saúde pública [Internet]. 2015 Dec [cited 2016 Jul 8];31(12):2523-34. Available from: http://www.ncbi.nlm.nih.gov/pubmed/26872229.

11. Stramrood CAI, Paarlberg KM. Huis In 't Veld EMJ, Berger LWAR, Vingerhoets AJJM, Schultz WCMW, et al. Posttraumatic stress following childbirth in homelike- and hospital settings. J Psychosom 
Obstet Gynaecol [Internet]. 2011 Jun [cited 2016 Jul 8];32(2):88-97. Available from: http://www.ncbi.nlm.nih.gov/pubmed/21557681.

12. Wijma K, Söderquist JWB. Posttraumatic stress disorder after childbirth: a cross sectional study. J Anxiety Disord [Internet]. 1997;11(6):587-97. Available from: http://www.ncbi.nlm.nih.gov/pubmed/9455721/.

13. Sderquist J, Wijma B, Thorbert G, Wijma K. Risk factors in pregnancy for post-traumatic stress and depression after childbirth. BJOG An Int J Obstet Gynaecol. 2009.

14. Modarres M, Afrasiabi S, Rahnama P, Montazeri A. Prevalence and risk factors of childbirth-related post-traumatic stress symptoms. BMC Pregnancy Childbirth [Internet]. 2012 [cited $2016 \mathrm{Jul}$ 30];12:88. Available from: http://www.ncbi.nlm.nih.gov/pubmed/22938705.

15. Adewuya A, Ologun Y, Ibigbami O. Post-traumatic stress disorder after childbirth in Nigerian women: prevalence and risk factors. BJOG An Int J Obstet Gynaecol [Internet]. 2006 Mar [cited 2016 Jul 8];113(3):284-8. Available from: http://doi.wiley.com/10.1111/j.1471-0528.2006.00861.x.

\section{Figures}

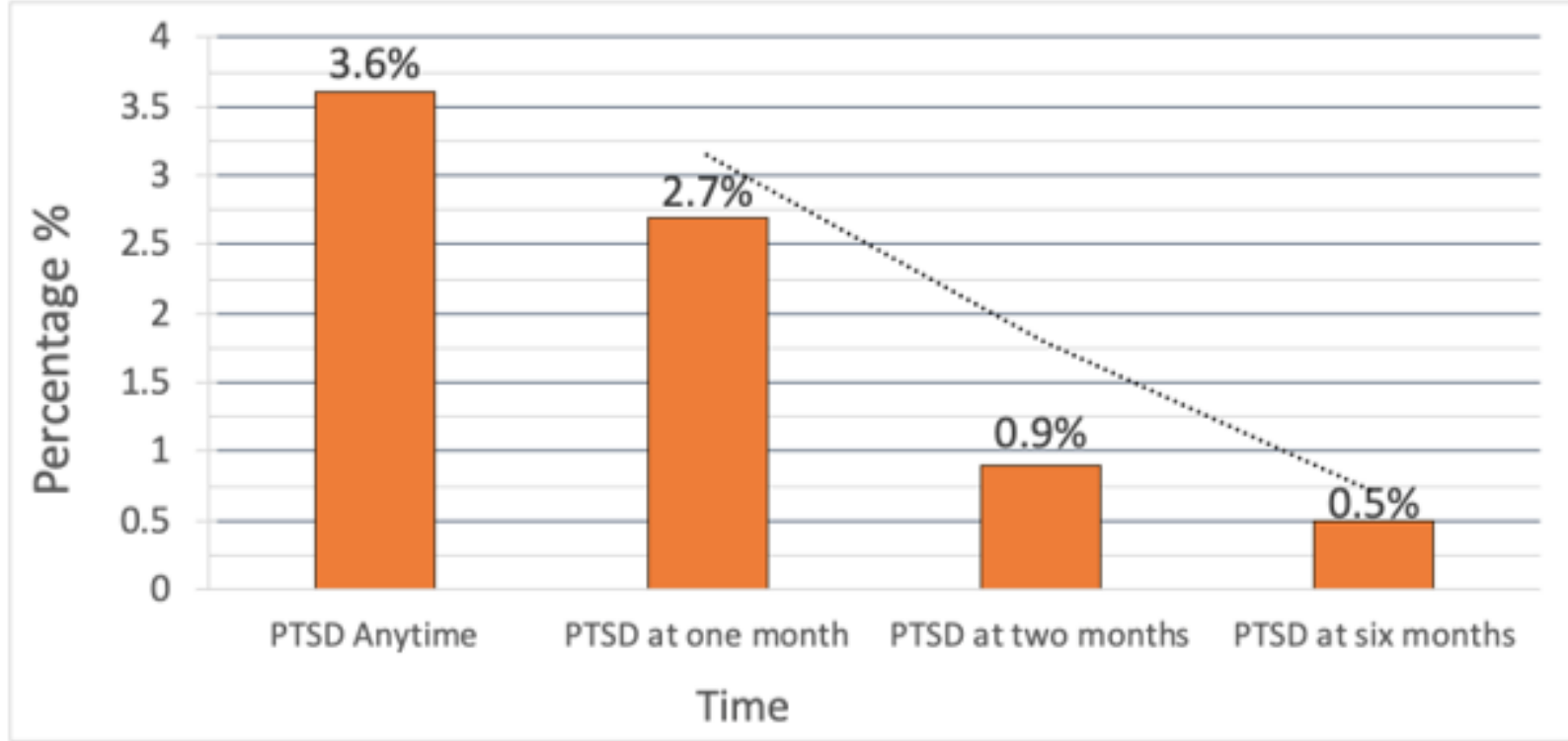

Figure 1

summarizes the prevalence of PTSD during the study period. 


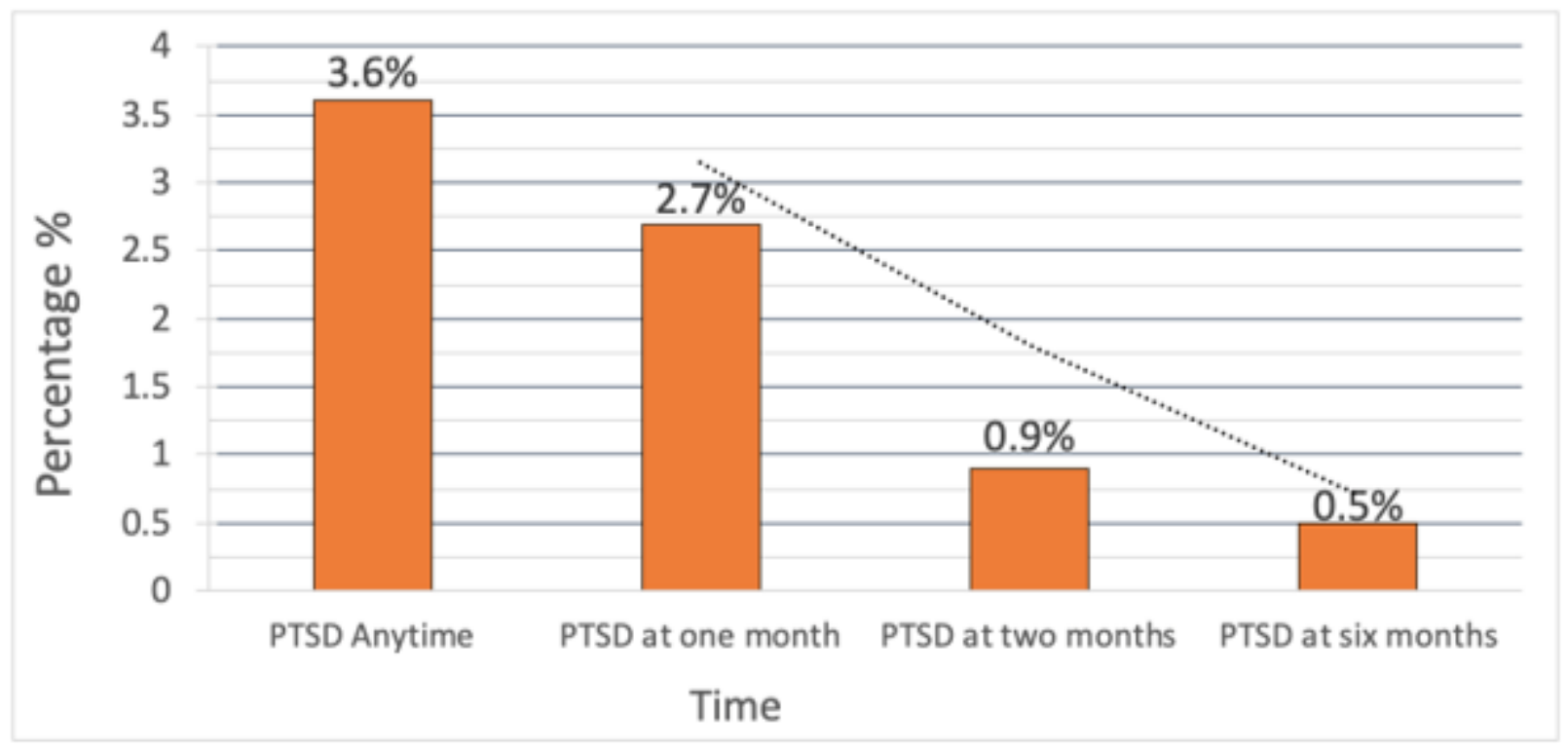

Figure 1

summarizes the prevalence of PTSD during the study period. 